\title{
D2EHPA-impregnated alumina for adsorption of strontium ions in environmental samples
}

\author{
H. Sid Kalal ${ }^{1} \cdot$ M. Abdollahi ${ }^{2} \cdot$ M. Ashoor ${ }^{1} \cdot$ E. Seyedkalal $^{3}$
}

Received: 6 June 2015/Revised: 10 October 2015/Accepted: 8 February 2016/Published online: 22 February 2016

(C) Islamic Azad University (IAU) 2016

\begin{abstract}
The alumina impregnated by the di-2-ethyl hexyl phosphoric acid was introduced to make more adsorption of strontium as well as to determine the optimal conditions. The influence of various parameters such as $\mathrm{pH}$, equilibrium time, adsorbent mass, interfering ions, and various eluant agents for the desorption of the strontium ions, initial concentration, and temperature was investigated to find out the adsorption behavior of the adsorbent under different conditions. The adsorbent was characterized by the Fourier transform infrared spectroscopy. The experimental data were fitted on the two-parameter and three-parameter adsorption isotherm models. The Freundlich and Redlich-Peterson models have suitable fitting on the experimental data $\left(R^{2}=0.9307\right)$. The kinetic models of adsorption were analyzed by the pseudo-firstand pseudo-second-order models. The results have been indicated that the pseudo-second-order kinetic model is more appropriate than the others. Advantages of our method were simple operation, less time for preparation of adsorbent, rapid phase separation, and capability to combine with various detection techniques. The method has been utilized to extract and the recovery of strontium ions in environmental aqueous samples.
\end{abstract}

H. Sid Kalal

hsidkalal@aeoi.org.ir

1 NFCRS, Nuclear Science and Technology Research Institute, AEOI, P.O. Box 11365-3486, Tehran, Iran

2 Department of Chemical Engineering, Tarbiat Modares University, Jalal Al Ahmad High Way, 14115-143 Tehran, Iran

3 Education District 18, Khojasteh High-School, Tehran, Iran
Keywords Alumina - Strontium · Adsorption · Isotherms · D2EHPA

\section{Introduction}

Strontium may be harmful on the health and environment due to strontium ${ }^{90}$ being beta emission. One of the important compounds is strontium chromate, which is toxic with high capability in generation lung cancer and various diseases even at low amounts. It may create anemia, hypoxia, and cancer at too high uptake (MacMillan et al. 2002). Therefore, its removal has a key role to improve environment. Various methods such as precipitation, liquid-liquid extraction, ion-exchange chromatography, and adsorption were proposed to remove strontium from aqueous solutions. The performance of adsorption technique is better than the others due to simplicity, selectivity, and high efficiency (Hafizi et al. 2011).

As shown, the adsorption of $\mathrm{Sr}(\mathrm{II})$ ions from aqueous solutions may be carried out by various organic and inorganic adsorbents such as goethite, hematite, manganese dioxide, bentonite, kaolinite, montmorillonite, silica colloid, clay minerals, pecan shells, activated charcoal, zirconia-modified vermiculite, and activated carbon, which their specifications have been fully understood (Sahai et al. 2000; Karasyova et al. 1999; Hasany and Chandhary 1981; Liang et al. 1993; Jeong 2001; Papachristodoulou et al. 2002; Lu and Mason 2001; Cole et al. 2000; Shawabkeh et al. 2002; Qadeer et al. 1992; Siviah et al. 2004; Chegrouche et al. 2009).

In this study, a new adsorbent, namely alumina $\left(\mathrm{Al}_{2} \mathrm{O}_{3}\right)$ impregnated by the di-2-ethyl hexyl phosphoric acid (D2EHPA), was introduced to remove strontium ions from aqueous solutions, and the effects of adsorption parameters 
such as $\mathrm{pH}$, initial concentration of $\mathrm{Sr}$ (II), temperature, and interfering metals were investigated. Furthermore, the isotherm models at adsorption process such as two-parameter (Langmuir, Freundlich) and three-parameter modeling (Redlich-Peterson, Toth) were evaluated to find out the best adsorption process (Wang et al. 2008; Taffarel and Rubio 2009).

\section{Materials and methods}

Activated alumina has high adsorption capacity because of having porous structure, and high chemical activity on the surfaces. Thus, it may be widely employed to product adsorbent and catalyst with high porosity. The aluminum oxide, D2EHPA, and $\operatorname{Sr}\left(\mathrm{NO}_{3}\right)_{2}$ were used as the adsorbent, impregnated solution, and salt, respectively. Also, the hydrochloric acid, nitric acid, and ammonium nitrate were used as the washing solutions in the experiments. They are the Merck's products (Darmstadt, Germany). The methods of Fourier transform infrared spectroscopy (FTIR) and inductively coupled plasma atomic emission spectroscopy (ICP) have been employed to analyze the samples. The amounts of $\mathrm{pH}$ and metallic ions were measured by the Metrohm model $744 \mathrm{pH}$ meter (Zofingen, Switzerland) and the 150AX ICP-OES-Varian Turbo instrument. Infrared spectra were obtained by the Vector 22-FTIR spectrometer, (Bruker, Germany) via the potassium bromide pellet method.

\section{Modification of adsorbent}

To impregnate adsorbent, the $1-\mathrm{g}$ powdered alumina was combined in the D2EHPA and ethanol solutions by the shaker at rotational speed of $180 \mathrm{rpm}$ for $24 \mathrm{~h}$. To test, the ratio of D2EHPA to ethanol was considered as 1:1, 2:1, and 1:2. The optimum ratio was found to be $1: 1$. Finally, the solution was filtered, and the absorbent was dried in an oven at $50{ }^{\circ} \mathrm{C}$ for $72 \mathrm{~h}$.

\section{Adsorption experiment}

The adsorption experiments were carried out in polyethylene tubes with $20 \mathrm{ml} \mathrm{Sr}$ ion solution in a thermostatic shaker bath, GFL-1083 model at rotational speed of $180 \mathrm{rpm}$ for $5 \mathrm{~h}$, and then the solutions were separated from the solids by filtration. The concentration of residual $\mathrm{Sr}$ ion solutions was measured by the ICP instrument. One may calculate the absorption yields (\%) as follows,

Ads yield $(\%)=\frac{\left(C_{i}-C_{e}\right)}{C_{i}} \times 100$

where $C_{i}$ and $C_{e}$ are the initial and equilibrium concentrations of the solution, respectively.

\section{Results and discussion}

\section{Characterization of impregnated resin}

Figure 1 shows the FTIR spectra of the $\mathrm{Al}_{2} \mathrm{O}_{3}$, D2EHPA, and $\mathrm{Al}_{2} \mathrm{O}_{3}$-D2EHPA. The intensity of $\mathrm{Al}_{2} \mathrm{O}_{3}$-D2EHPA is higher than the others. The characteristic bands of $\mathrm{P}=\mathrm{O}, \mathrm{P}-$ $\mathrm{O}-\mathrm{C}$, or $\mathrm{P}-\mathrm{O}-\mathrm{H}$ and $\mathrm{O}-\mathrm{H}$ were $1247,1054,1480$, and $3500 \mathrm{~cm}^{-1}$, respectively (Khaldun et al. 2008; Vellaichamy and Palanivelu 2011).

\section{Effect of adsorbent' amount}

The various values of adsorbent $(0.02,0.05,0.1,0.2,0.5$, $0.75,1 \mathrm{~g}$ ) in filled batch of $20 \mathrm{~mL} \mathrm{Sr}$ ion solution with the concentration of $5 \mathrm{mg} / \mathrm{L}$ at $25{ }^{\circ} \mathrm{C}$ for $5 \mathrm{~h}$ were used. The results have been indicated that at low values of adsorbent, the percentage of adsorption will be increased with increasing adsorbent, and then it will be invariant at high values, as shown in Fig. 2. The optimum amount of adsorbent was $0.2 \mathrm{~g}$, leading to adsorption of $96 \%$. All subsequent experiments were carried out at this optimum value.

\section{Effect of initial concentration}

The various initial concentrations were investigated to find out the best adsorption. The six concentrations at values of 0 through $3 \mathrm{mg} / \mathrm{L}$ in $20 \mathrm{~mL} \mathrm{Sr}$ ion solution with $0.2-\mathrm{g}$ adsorbent were used. The experimental results have been demonstrated that the strontium adsorption is dependent to the initial concentrations as a function of parabolic in which the maximum value of $87.5 \%$ is at $2 \mathrm{mg} / \mathrm{L}$, as shown in Fig. 3.

\section{Effect of pH}

The $\mathrm{pH}$ values of 3 through 12 were considered at initial concentration of $5 \mathrm{mg} / \mathrm{L}$. The acid or base was used to adjust the $\mathrm{pH}$. The results show that the best $\mathrm{pH}$ is 5.8 with adsorption of $98 \%$, as shown in Fig. 4. The percentage amount of adsorption is decreased by increasing the $\mathrm{pH}$ value because the $\mathrm{Sr}$ ion has the positive charge. All of subsequent experiments were carried out at the $\mathrm{pH} 5.8$.

\section{Desorption study}

The $\mathrm{Sr}(\mathrm{II})$ desorption with $10 \mathrm{ml}$ solutions of $5 \mathrm{M}-\mathrm{HCl}$, $\mathrm{HNO}_{3}$, and $\mathrm{NH}_{4} \mathrm{NO}_{3}$ at the $\mathrm{pH} 5.8$ was investigated. The $5 \mathrm{M}-\mathrm{HCL}$ solution is better than the others because of having the desorption efficiency value of $79.5 \%$. The efficiency values for the solutions of $\mathrm{NH}_{4} \mathrm{NO}_{3}$ and $\mathrm{HNO}_{3}$ were 69 and $38 \%$, respectively. 
Fig. 1 FTIR spectra of pure $\mathrm{Al}_{2} \mathrm{O}_{3}$, D2EHPA, and $\mathrm{Al}_{2} \mathrm{O}_{3}$ impregnated with D2EHPA

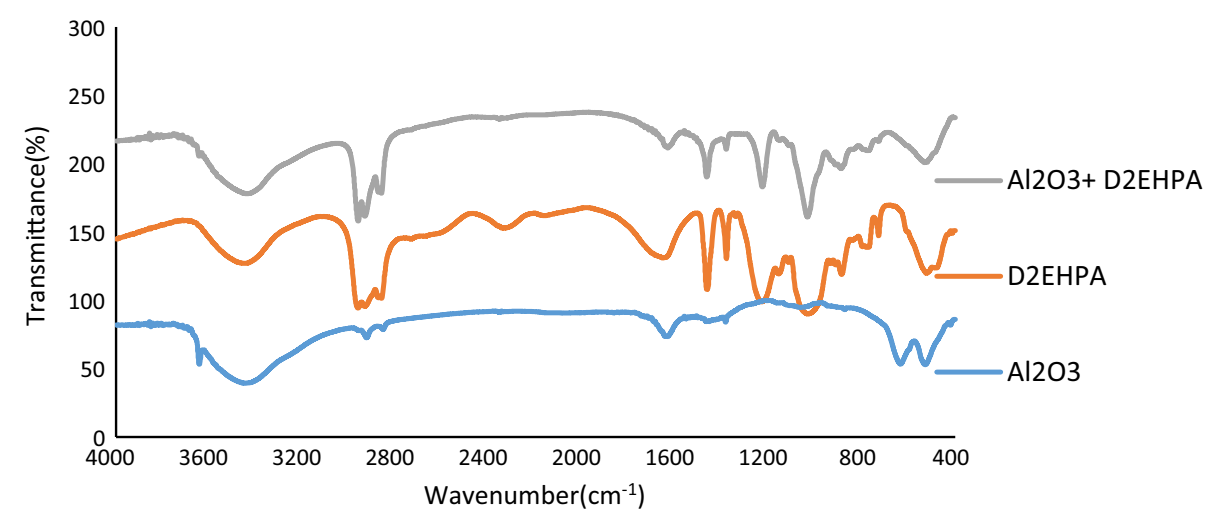

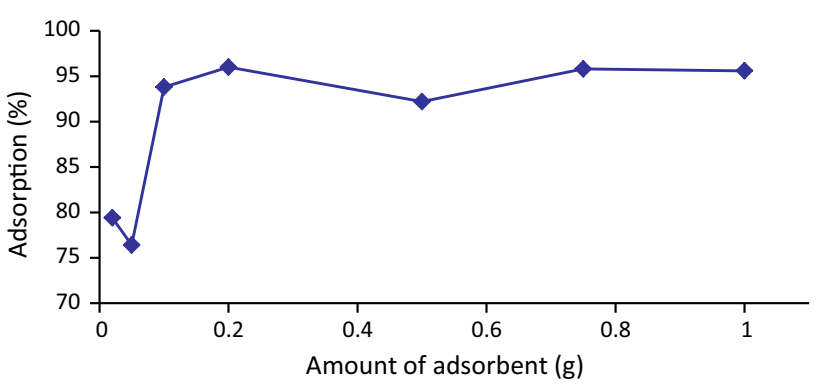

Fig. 2 Effect of adsorbent dose on strontium removal onto alumina impregnated by D2EHPA

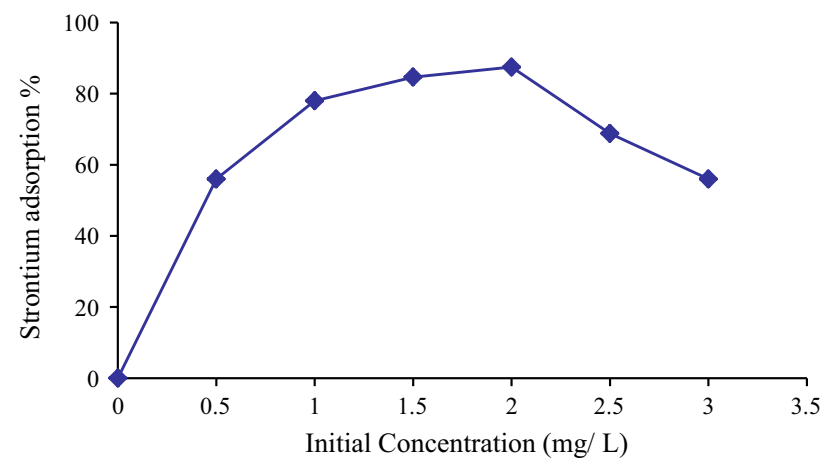

Fig. 3 Effect of initial concentration on adsorption

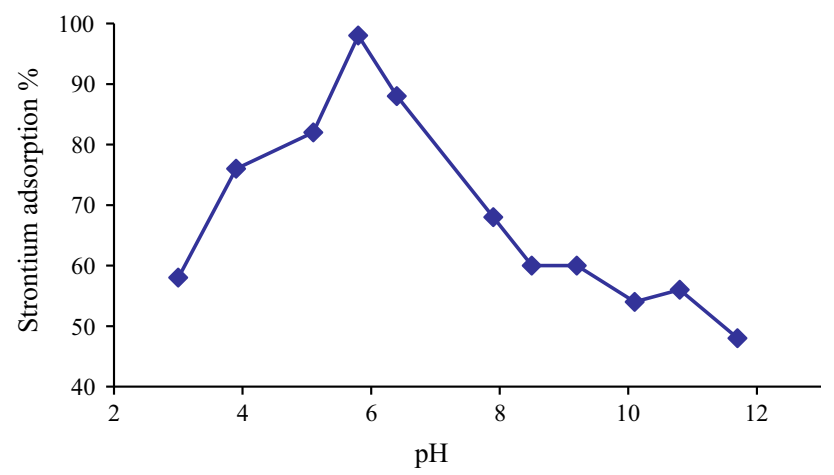

Fig. 4 Effect of $\mathrm{pH}$ on adsorption

\section{Effect of the adsorption time}

The adsorption time of strontium ions at different times ( 5 , $15,30,45,60,90$, and $120 \mathrm{~min}$ ) was carried out. The $0.2-\mathrm{g}$ $\mathrm{Al}_{2} \mathrm{O}_{3}$-D2EHPA adsorbent was shaken at $20 \mathrm{~mL}$ solution containing strontium $5 \mathrm{mg} / \mathrm{L}$. After filtering the adsorbent, the concentration of strontium ions was determined by the ICP-AES using the recommended batch method. The adsorption as a function of contact time is as exponential at the times less than $30 \mathrm{~min}$, and it will approach to the distinct value with increasing time. The adsorption value was $42.5 \%$ at the time of $5 \mathrm{~min}$, as shown in Fig. 5.

\section{Effect of temperature}

The adsorption capacity was investigated at various temperatures $\left(20,32\right.$, and $\left.44{ }^{\circ} \mathrm{C}\right)$ and initial concentrations of 5, 10, 15, $20 \mathrm{mg} / \mathrm{L}$, as shown in Fig. 6 and Tables 1, 2. In all experiments, volume of solution and amount of adsorbent were $20 \mathrm{~mL}$ and $0.2 \mathrm{~g}$, respectively.

The thermodynamic parameters are considered to determine the effect of temperature on the adsorption capacity at initial concentrations of 5, 10, 15, $20 \mathrm{mg} / \mathrm{L}$ as follows (Cortés-Martínez et al. 2010),

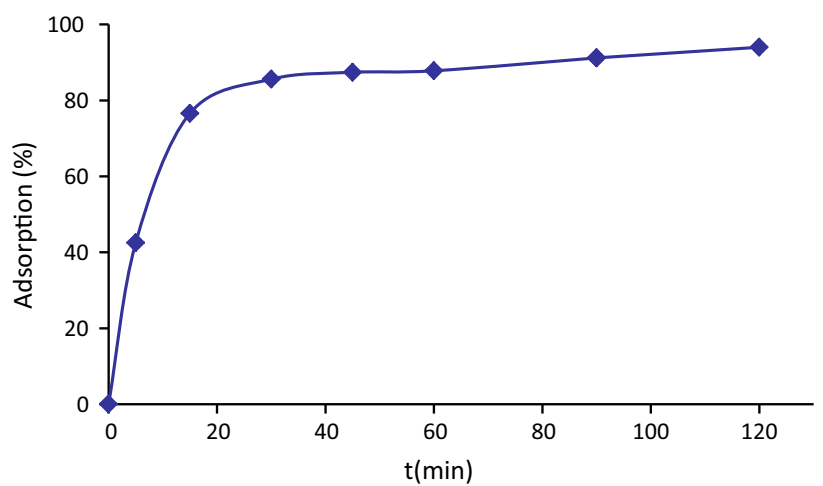

Fig. 5 Kinetics adsorption of $\mathrm{Sr}(\mathrm{II})$ ions on alumina impregnated by D2EHPA 


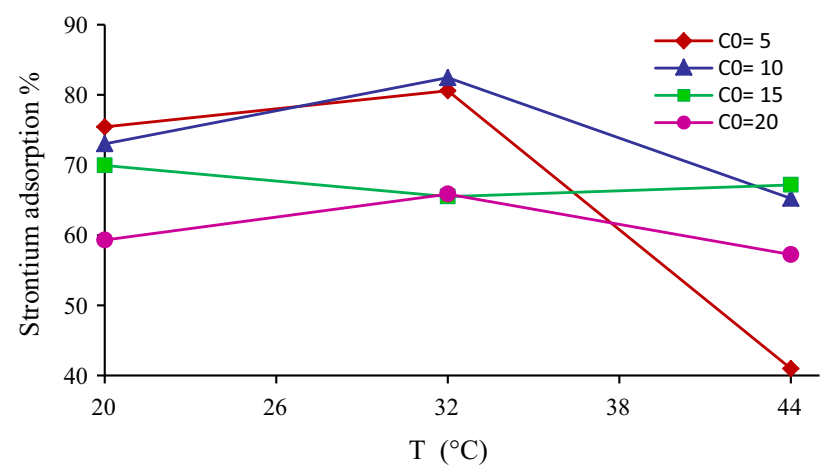

Fig. 6 Effect of temperature on adsorption percent

$\ln K_{D}=\frac{\Delta s^{\circ}}{R}-\frac{\Delta h^{\circ}}{R T}$

where $K_{d}, \Delta S^{\circ}, \Delta H^{\circ}, T$, and $R$ are the distribution coefficient of strontium, standard entropy, standard enthalpy, temperature in Kelvin, and the gas constant $(8.314 \mathrm{~J} / \mathrm{mol} \mathrm{K})$, respectively. The distribution coefficient $\left(K_{d}\right)$ of adsorbed strontium on the adsorbent is calculated as follows,

$K_{d}=\frac{C_{0}-C_{e}}{C_{e}} \times \frac{V}{m}$

where $C_{0}$ and $C_{\mathrm{e}}$ are the initial and equilibrium concentrations of the aqueous solution, respectively. The $\mathrm{V}(\mathrm{mL})$ and $m(\mathrm{~g})$ are the volume of the solution and the mass of adsorbent. The standard Gibbs free energy, $\Delta G^{\circ}$, is calculated by the following well-known equation,

$\Delta G^{\circ}=\Delta H^{\circ}-T \Delta S^{\circ}$

Table 1 The adsorption results in various temperatures

\begin{tabular}{|c|c|c|c|c|c|c|}
\hline \multirow[t]{2}{*}{$C_{0}\left(\mathrm{mg} \mathrm{L}^{-1}\right)$} & \multicolumn{2}{|c|}{$20\left({ }^{\circ} \mathrm{C}\right)$} & \multicolumn{2}{|c|}{$32\left({ }^{\circ} \mathrm{C}\right)$} & \multicolumn{2}{|c|}{$44\left({ }^{\circ} \mathrm{C}\right)$} \\
\hline & \multicolumn{2}{|c|}{$C_{E}$ Ads $(\%)$} & \multicolumn{2}{|c|}{$C_{E}$ Ads $(\%)$} & \multicolumn{2}{|c|}{$C_{E}$ Ads (\%) } \\
\hline 5 & 1.228 & 75.44 & 0.971 & 80.58 & 2.951 & 40.98 \\
\hline 7.5 & 1.961 & 73.85 & 2.137 & 71.50 & 3.531 & 52.92 \\
\hline 10 & 2.698 & 73.02 & 1.755 & 82.45 & 3.475 & 65.25 \\
\hline 15 & 4.507 & 69.95 & 5.174 & 65.50 & 4.925 & 67.17 \\
\hline 17.5 & 4.602 & 73.70 & 5.343 & 69.47 & 6.396 & 63.45 \\
\hline 20 & 8.139 & 59.30 & 6.828 & 65.86 & 8.554 & 57.23 \\
\hline
\end{tabular}

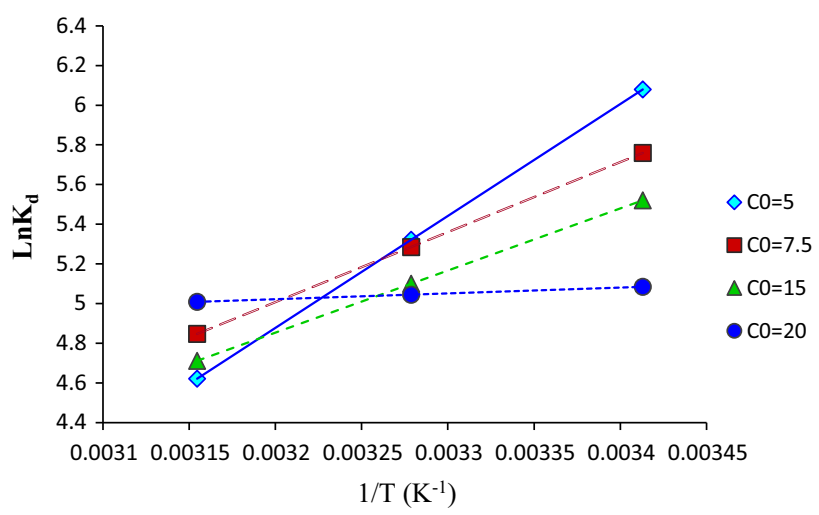

Fig. 7 Effect of temperature on $\operatorname{Ln} K_{d}$

The effect of temperature on distribution coefficient $\left(K_{d}\right)$ of strontium is shown in Fig. 7 and Table 2. This coefficient is increased with increasing the temperature at various concentrations.

The $\Delta S^{\circ}, \Delta H^{\circ}$, and $\Delta G^{\circ}$ were measured at the different concentrations, as indicated in Table 2. The $\Delta G^{\circ}$ was negative for all initial concentrations because of being the spontaneous nature of the adsorption process. In contrast, this value will be increased with increasing initial concentration at the temperatures of 293 and 305 , but at $317 \mathrm{~K}$ this value will be decreased.

\section{Adsorption isotherms}

Four different adsorption isotherm models containing two parameter (Langmuir-Freundlich) and three parameter (Toth-Redlich-Peterson) were considered to explain the equilibrium data. These models are commonly used to investigate the adsorption isotherm before.

\section{Langmuir isotherm}

The most common model is the Langmuir model. This is used to quantify the amount of adsorbate adsorbed on an adsorbent as a function of partial pressure of gas or concentration of liquidate at a distinct temperature. This empirical model assuming monolayer adsorption (the adsorbed layer is one molecule in thickness) may occur at a distinct number of the similar localized sites, without
Table 2 Thermodynamic parameters for strontium adsorption on alumina impregnated by D2EHPA

\begin{tabular}{llllll}
\hline$C_{0}\left(\mathrm{mgL}^{-1}\right)$ & $\Delta H\left(\mathrm{~kJ} \mathrm{~mol}^{-1}\right)$ & $\Delta S\left(\mathrm{~kJ} \mathrm{~mol}^{-1} \mathrm{~K}^{-1}\right)$ & \multicolumn{4}{l}{$\Delta G\left(\mathrm{~kJ} \mathrm{~mol}^{-1}\right)$} & \\
\cline { 4 - 6 } & & & $293 \mathrm{~K}$ & $305 \mathrm{~K}$ & $317 \mathrm{~K}$ \\
\hline 5 & -46.9408 & -0.10966 & -14.8104 & -13.4945 & -12.1786 \\
7.5 & -29.3401 & -0.05226 & -14.0279 & -13.4008 & -12.7737 \\
15 & -26.0394 & -0.04297 & -13.4492 & -12.9336 & -12.4179 \\
20 & -2.4717 & 0.03384 & -12.3868 & -12.7929 & -13.1990 \\
\hline
\end{tabular}


lateral interaction and steric hindrance between the adsorbed molecules, even on adjacent sites (Vijayaraghavan et al. 2006). One may obtain the equilibrium concentration as follows,

$q_{e}=\frac{q_{m} K_{L} C_{e}}{\left(1+K_{L} C_{e}\right)}$

where $K_{L}$ and $q_{m}$ are the Langmuir constant and the maximum amount of adsorption capacity $(\mathrm{mg} / \mathrm{g})$, respectively. The $q_{e}$ and $C_{e}$ are equilibrium concentrations in solid and liquid phases, respectively.

\section{Freundlich isotherm}

The Freundlich isotherm is a curve related to the concentration of a solute on the surface of an adsorbent to the concentration of the solute in the liquid phase (Freundlich 1906). This model may be applied to multilayer adsorption, with non-uniform distribution of adsorption heat and affinities over the heterogeneous surface (Adamson and Gast 1997). It is stated as follows,

$q_{e}=K_{F} C_{e}^{\frac{1}{n}}$

The $K_{F}$ and $n$ refer to the Freundlich constants, and the $q_{e}$ and $C_{e}$ are equilibrium concentration in solid and liquid phases, respectively.

\section{Toth isotherm}

The Toth isotherm was developed to yield an improved fit versus traditional Langmuir isotherm modeling (Tóth 2000). This model is useful to describe heterogeneous systems and approaches to the Henry region at infinite dilution. It may be rearranged to give a linear transform as follows,

$q_{e}=\frac{K_{T 1} C_{e}}{\left(K_{T 2}+C_{e}^{n}\right)^{1 / n}}$

where $q_{e}, C_{e}$, and $n$ are the amount of adsorbed material (mg/ $\mathrm{g})$, the concentration of the adsorbate $(\mathrm{mg} / \mathrm{L})$ at equilibrium, and the Toth model exponent, respectively. The $K_{T 1}$ and $K_{T 2}$ are the Toth maximum adsorption capacity $(\mathrm{mg} / \mathrm{g})$ and the Toth equilibrium constant, respectively.

\section{Redlich-Peterson isotherm}

The Redlich-Peterson isotherm is a hybrid of the Langmuir and Freundlich isotherms (Redlich and Peterson 1959). The numerator is from the Langmuir isotherm and has the benefit of approaching to the Henry region at infinite dilution. The denominator has the hybrid Langmuir-Freundlich form as follows,
Table 3 Equilibrium data of impregnated alumina for $\mathrm{Sr}$ ions

\begin{tabular}{ll}
\hline $\mathrm{Sr}$ & \\
\hline$Q_{e}\left(\mathrm{mg} \mathrm{g}^{-1}\right)$ & $C_{e}\left(\mathrm{mg} \mathrm{L}^{-1}\right)$ \\
\hline 0 & 0 \\
0.4029 & 0.971 \\
0.5363 & 2.137 \\
0.8245 & 1.755 \\
0.9826 & 5.174 \\
1.2157 & 5.343 \\
1.3172 & 6.828 \\
\hline
\end{tabular}

Table 4 The parameters of isotherm models for $\mathrm{Sr}$ ions

\begin{tabular}{ll}
\hline Name of isotherm & Known parameters \\
\hline Langmuir & $q_{m}=1.926$ \\
& $k_{L}=0.2731$ \\
& $R^{2}=0.9241$ \\
& $k_{F}=0.455$ \\
Freundlich & $n=1.845$ \\
& $R^{2}=0.9307$ \\
& $k_{T 1}=72.69$ \\
Toth & $k_{T 2}=1.328$ \\
& $n=0.1668$ \\
& $R^{2}=0.9297$ \\
& $k_{R P 1}=3253$ \\
Redlich-Peterson & $k_{R P 2}=7147$ \\
& $n=0.4581$ \\
& $R^{2}=0.9307$ \\
\hline
\end{tabular}

$k_{L}$ Langmuir constant, $q_{m}$ Maximum amount of adsorption capacity, $k_{F}$ and $n$ Freundlich constants, $q_{e}$ and $C_{e}$ Equilibrium concentration in solid and liquid phases, $q_{e}, C_{e}$ and $n$ Amount of adsorbed material, the concentration of the adsorbate at equilibrium, and the Toth model exponent, $k_{T 1}$ and $k_{T 2}$ Toth maximum adsorption capacity and the Toth equilibrium constant, $k_{R P 1}, k_{R P 2}$ and $n$ Redlich-Peterson isotherm constant, a constant, and an exponent that lies within 0 and 1 , $C_{e}$ and $q_{e}$ Equilibrium liquid-phase concentration of the adsorbate and the equilibrium adsorbate loading onto the adsorbent

$q_{e}=\frac{K_{R P 1} C_{e}}{1+K_{R P 2} C_{e}^{n}}$

where $K_{R P 1}, K_{R P 2}$, and $n$ are the Redlich-Peterson isotherm constant (L/g), a constant ( $\mathrm{L} / \mathrm{mg})$, and an exponent that lies within 0 and 1 , respectively. The $C_{e}$ and $q_{e}$ are the equilibrium liquid-phase concentration of the adsorbate $(\mathrm{mg} / \mathrm{L})$ and the equilibrium adsorbate loading onto the adsorbent $(\mathrm{mg} / \mathrm{g})$, respectively.

The equilibrium data of impregnated alumina are indicated in Table 3 at $32{ }^{\circ} \mathrm{C}$, and the various parameters of isotherm models using the equilibrium experimental data are listed in Table 4. The Freundlich and Redlich-Peterson 
Fig. 8 a Pseudo-first-order and b pseudo-second-order kinetics on alumina impregnated by D2EHPA at different concentrations

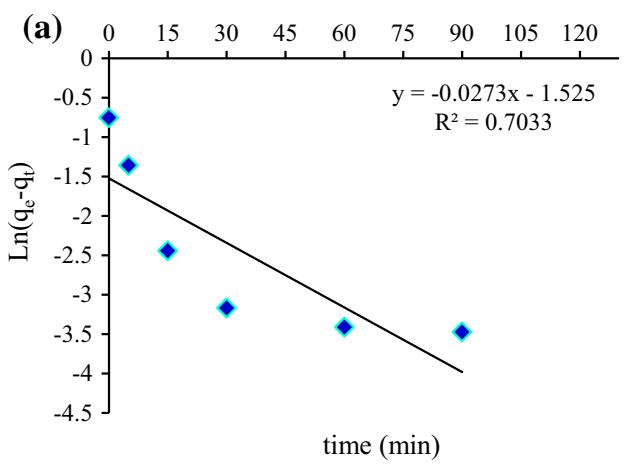

models have suitable fitting on the experimental data $\left(R^{2}=0.9307\right)$.

\section{Study of adsorption kinetics}

One of the most important characteristics is the solute uptake rate that represents the adsorption efficiency of the adsorbent. The adsorption process was initially fast $(0$ $15 \mathrm{~min}$ ) and then was more slowly with increasing time, and the equilibrium state was at the times of 15 till $120 \mathrm{~min}$. To analyze the adsorption rate of $\mathrm{Sr}$ ion on impregnated alumina, Eqs. (10) and (11) were considered based on the experimental data as follows (Ho and McKay 1999; Alihosseini et al. 2010),

$\log \left(q_{e}-q_{t}\right)=\log q_{e}-k_{1} t$

$\frac{t}{q_{t}}=\frac{1}{2 k_{2} q_{e}^{2}}+\frac{t}{q_{e}}$

where $k_{1}$ and $k_{2}$ are the Lager green adsorption rate constant $\left(\mathrm{h}^{-1}\right)$ and the pseudo-second-order adsorption rate constant $(\mathrm{g} / \mathrm{mg} \mathrm{h})$, and the $q_{e}$ and $q_{t}$ are the amounts of metal ions absorbed $(\mathrm{mg} / \mathrm{g})$ at equilibrium and at time of $t$, respectively. The plots of $\log \left(q_{e}-q_{t}\right)$ and $t / q_{t}$ versus $t$ are shown in Fig. 8. The pseudo-second-order kinetic model provides a correlation for the adsorption of $\mathrm{Sr}$ ions on the impregnated alumina better than the pseudo-first-order model. In addition, the correlation coefficient of the pseudo-second-order kinetic model is more than that of the pseudo-first-order kinetic model (Table 4). The best fit was carried out at temperature of $32{ }^{\circ} \mathrm{C}$, as shown in Fig. 9 .

\section{Effect of other ions}

The effect of other ions $(5 \mathrm{mg} / \mathrm{L})$ such as $\mathrm{Ca}^{+2} \mathrm{Ni}^{+2}, \mathrm{Fe}^{+2}$, $\mathrm{Mg}^{+2}, \mathrm{Ba}^{+2}, \mathrm{Cd}^{+2}, \mathrm{Al}^{+3}$, and $\mathrm{Na}^{+}$on the uptake of $\mathrm{Sr}(\mathrm{II})$ ions (concentration $5 \mathrm{mg} / \mathrm{L}$ ) was investigated here. One may calculate the extraction percentage (E \%) by the following equations,

$Q=\left(C_{0}-C e\right) V / W$

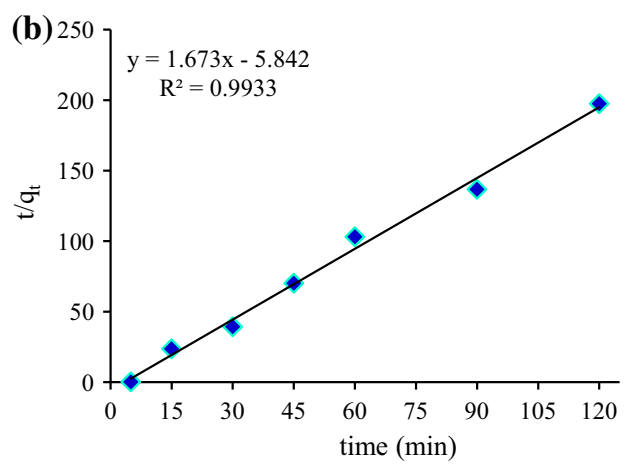

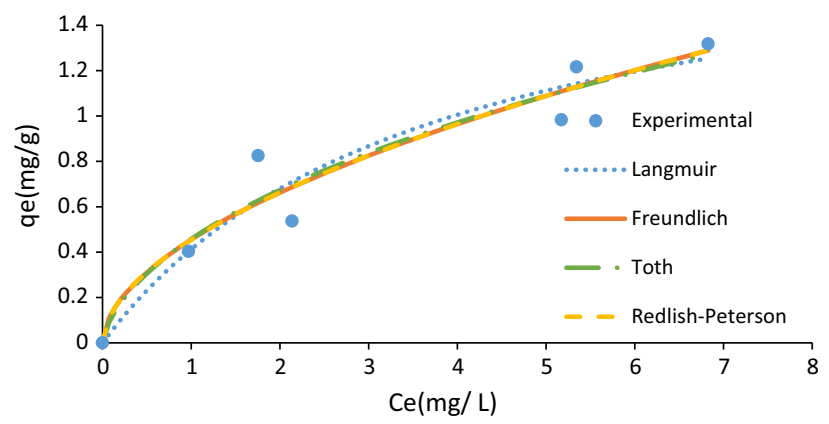

Fig. 9 Best nonlinear isotherms for the adsorption of strontium (II) ions at $32{ }^{\circ} \mathrm{C}$

Table 5 Effect of interfering ions on the adsorption of $\mathrm{Sr}$ (II) ions

\begin{tabular}{lllll}
\hline Interfering ion & $\mathrm{A}\left(\mathrm{mg} \mathrm{L}^{-1}\right)$ & $\% L$ & $\% E$ & $D$ \\
\hline- & 4.58 & 0 & 91.6 & 9.16 \\
$\mathrm{Ca}^{+2}$ & 3.0 & 34.49 & 60 & 6.0 \\
$\mathrm{Ni}^{+2}$ & 3.82 & 16.59 & 76.4 & 7.64 \\
$\mathrm{Fe}^{+2}$ & 3.69 & 19.43 & 73.8 & 7.38 \\
$\mathrm{Mg}^{+2}$ & 2.24 & 51.09 & 44.8 & 4.48 \\
$\mathrm{Ba}^{+2}$ & 3.52 & 23.14 & 70.4 & 7.04 \\
$\mathrm{Cd}^{+2}$ & 3.92 & 14.41 & 78.4 & 7.84 \\
$\mathrm{Al}^{+3}$ & 3.17 & 30.78 & 63.4 & 6.34 \\
$\mathrm{Na}^{+}$ & 3.03 & 33.84 & 60.6 & 6.06 \\
Mixed above & 1.74 & 62.01 & 34.8 & 3.48 \\
\hline
\end{tabular}

$A$ amount of adsorbed $\mathrm{Sr}$ (II) $\left(\mathrm{mg} \mathrm{L}^{-1}\right), L$ loss adsorption (\%), $E$ extraction percentage $(\%), D$ distribution ratio

$E=C_{e} / C_{0}$

$D=E V / W$

$L=C_{e}^{N o-i o n}-C_{e} / C_{e}^{N o-i o n}$

where $Q$ is the adsorbent capacity $(\mathrm{mg} / \mathrm{g})$, the $C_{o}$ and $C_{e}$ stand for the initial and equilibrium concentrations $(\mu \mathrm{g} /$ $\mathrm{mL}$ ), and the $W, V$, and $E \%$ are the mass of adsorbent $\mathrm{Al}_{2} \mathrm{O}_{3} / \mathrm{D} 2 \mathrm{EHPA}(0.2 \mathrm{~g})$, the volume of solution $(0.02 \mathrm{~L})$, and the extraction percentage, respectively. The interfering 
Table 6 Results of $\operatorname{Sr}(\mathrm{II})$ recovery after spiking in various water samples

\begin{tabular}{|c|c|c|c|c|}
\hline Sample & $\begin{array}{l}\text { Spiked } \\
\left(\mathrm{mg} \mathrm{L}^{-1}\right)\end{array}$ & STD & $\begin{array}{l}\text { Found } \\
\left(\mathrm{mg} \mathrm{L}^{-1}\right)\end{array}$ & ${ }^{\mathrm{a}}$ Recovery $\%+\operatorname{RSD} \%$ \\
\hline \multirow{3}{*}{ Tap } & 0.0 & 0.006 & 0.153 & - \\
\hline & 0.2 & 0.015 & 0.356 & $100.8 \pm 4.28$ \\
\hline & 0.4 & 0.010 & 0.560 & $101.2 \pm 1.79$ \\
\hline \multirow{3}{*}{$\begin{array}{l}\text { Well } \\
\text { Water }\end{array}$} & 0.0 & 0.058 & 3.567 & - \\
\hline & 0.2 & 0.252 & 3.630 & $96 \pm 6.92$ \\
\hline & 0.4 & 0.058 & 4.130 & $104 \pm 1.4$ \\
\hline \multirow{3}{*}{$\begin{array}{l}\text { River } \\
\text { Water }\end{array}$} & 0.0 & 0.100 & 8.700 & - \\
\hline & 0.2 & 0.100 & 8.900 & $100 \pm 1.12$ \\
\hline & 0.4 & 0.100 & 9.100 & $100 \pm 1.10$ \\
\hline
\end{tabular}

$S D$ standard deviation

$R S D$ relative standard deviation

${ }^{\text {a }}$ For three determinations

ions have negligible effect on $\mathrm{Sr}$ (II) uptake, as listed in Table 5.

\section{Analysis of the real samples}

To examine the ability of the impregnated adsorbent under optimal conditions, we have estimated the adsorption of the Sr (II) ions in various environmental aqueous samples. Table 6 shows the results of recovery of three different samples under the similar conditions with high recovery in which is defined as follows,

$\operatorname{Recovery}_{(N+1)} \%=\frac{C_{\text {Found }(N+1)}}{C_{\text {Spiked }(N+1)}+C_{\text {Found }(N)}} \times 100$

\section{Conclusion}

In this study, the adsorption of $\mathrm{Sr}^{2+}$ was investigated by the D2EHPA-impregnated alumina at batch process. The effect of $\mathrm{pH}$, contact time, mass of adsorbent, initial concentration, and temperature was evaluated to determine the optimum conditions of strontium adsorption. The results have been indicated that the optimum conditions of adsorption were at pH 5.8, mass of adsorbent $0.2 \mathrm{~g}$, initial concentration $2 \mathrm{mg} /$ $\mathrm{L}$, and temperature $32{ }^{\circ} \mathrm{C}$. Also, the experimental data were fitted into various adsorption isotherm models. The Freundlich and Redlich-Peterson models have suitable fitting on the experimental data with $R^{2}=0.9307$. The kinetic models of adsorption were analyzed by pseudo-first- and pseudo-second-order models. The results have been illustrated that the pseudo-second-order kinetic model was more appropriate than the others. Advantages of our method were simple operation, less time for preparation of adsorbent, rapid phase separation, and capability to combine with various detection techniques. We have investigated the effect of other ions such as $\mathrm{Ca}^{+2}, \mathrm{Ni}^{+2}, \mathrm{Fe}^{+2}, \mathrm{Mg}^{+2}, \mathrm{Ba}^{+2}$, $\mathrm{Cd}^{+2}, \mathrm{Al}^{+3}$, and $\mathrm{Na}^{+}$on the uptake of $\mathrm{Sr}$ (II) ions. The interfering ions have negligible effect on $\mathrm{Sr}$ (II) uptake. Moreover, the ability of the impregnated adsorbent under optimal conditions at the real samples was investigated, and we have estimated the adsorption of $\mathrm{Sr}$ (II) ions in various environmental aqueous samples.

Acknowledgments The authors wish to extend their gratitude and thanks from the nuclear science and technology research institute in Tehran for providing means and support required for implementation of this study.

\section{References}

Adamson AW, Gast AP (1997) Physical chemistry of surfaces, 6th edn. Wiley, New York

Alihosseini A, Taghikhani V, Safekordi AA, Bastani D (2010) Equilibrium sorption of crude oil by expanded perlite using different adsorption isotherms at $298.15 \mathrm{k}$. Int J Environ Sci Technol 7(3):591-598

Chegrouche S, Mellah A, Barkat M (2009) Removal of strontium from aqueous solutions by adsorption onto activated carbon: kinetic and thermodynamic studies. Desalination 235:306-318

Cole T, Bidoglio G, Soupioni M, O’Vorman M, Gibson N (2000) Diffusion mechanisms of multiple strontium species in clay. Geochim Cosmochim Acta 64:385-396

Cortés-Martínez R, Olguín MT, Solache-Ríos M (2010) Cesium sorption by clinoptilolite-rich tuffs in batch and fixed-bed systems. Desalination 258:164-170

Freundlich HMF (1906) Over the adsorption in solution. J Phys Chem 57:385-471

Hafizi M, Abolghasemi H, Moradi M, AlamdarMilani S (2011) Strontium adsorption from sulfuric acid solution by Dowex 50W-X resins. Chin J Chem Eng 19:267-272

Hasany SM, Chandhary MH (1981) Adsorption studies of strontium on manganese dioxide from aqueous solutions. Int J Appl Radiat Isot 32:899-904

Ho YS, McKay G (1999) Pseudo-second order model for sorption processes. Process Biochem 34:451-465

Jeong CH (2001) Mineralogical and hydrochemical effects on adsorption removal of Cs-137 and Sr-90 by kaolinite. J Environ Sci Health 36:1089-1099

Karasyova ON, Ivanova LI, Lakshtanov LZ, Lövgren L (1999) Strontium sorption on hematite at elevated temperatures. J Colloid Interface Sci 220:419-428

Khaldun I, Buchari SA, Dan Amran MB (2008) Separation of Sm(III) and $\mathrm{Gd}(\mathrm{III})$ using solvent-impregnated resin containing di-(2ethylhexyl) phosphoric acid (D2EHPA) and tributylphosphate (TBP). In: Proceeding of the international seminar on chemistry 79-82

Liang TJ, Hsu CN, Liou DC (1993) Modified Freundlich sorption of cesium and strontium on wyoming bentonite. Appl Radiat Isot 44:1205-1208

Lu N, Mason CFV (2001) Sorption-desorption behaviour of strontium-85 onto montmorillonite and silica. Colloids Appl Geochem 16:1653-1662

MacMillan JP, Park JW, Gerstenberg R, Wagner H, Köhler K, Wallbrecht P (2002) Strontium and strontium compounds. In: Ullmann's encyclopedia of industrial chemistry. Wiley: Weinheim 
Papachristodoulou CA, Assimakopoulos PA, Gangas NHJ (2002) Strontium adsorption proprieties of aluminium-pillared montmorillonite carrying carboxylate functional groups. J Colloid Interface Sci 245:32-39

Qadeer R, Hanif J, Saleem M, Afzal M (1992) Selective adsorption of strontium on activated charcoal from electrolytic aqueous solutions. Collect Czechoslov Chem Commun 57:2065-2072

Redlich O, Peterson DL (1959) A useful adsorption isotherm. J Phys Chem 63:1024-1026

Sahai N, Caroll SA, Roberts S, O’Day PA (2000) X-ray adsorption spectroscopy of strontium(II) coordination: II. Sorption and precipitation at kaolinite, amorphous silica and goethite surfaces. J Colloid Interface Sci 222:198-212

Shawabkeh RA, Rockstraw DA, Bhada RK (2002) Copper and strontium adsorption by a novel carbon material manufactured from pecan shells. Carbon 40:781-786

Siviah MV, Kumar SS, Venkatesan KA, Sasidhar P, Krishna RM, Murthy GS (2004) Sorption of strontium on zirconia modified vermiculite. J Nucl Radiochem Sci 5:33-36
Taffarel SR, Rubio J (2009) On the removal of Mn2+ ions by adsorption onto natural and activated Chilean zeolites. Miner Eng 22:336-343

Tóth J (2000) Calculation of the BET-compatible surface area from any type I isotherms measured above the critical temperature. J Colloid Interface Sci 225:378-383

Vellaichamy S, Palanivelu K (2011) Preconcentration and separation of copper, nickel and zinc in aqueous samples by flame atomic absorption spectrometry after column solid-phase extraction onto MWCNTs impregnated with D2EHPA-TOPO mixture. J Hazard Mater 185:1131-1139

Vijayaraghavan K, Padmesh TVN, Palanivelu K, Velan M (2006) Biosorptionofnickel(II) ions onto Sargassumwightii: application of two-parameter and three parameter isotherm models. J Hazard Mater 133:304-308

Wang Y, Ye L, Yuehua H (2008) Adsorption mechanisms of Cr(VI) on the modified bauxite tailings. Miner Eng 21:913-917 